\title{
Article
}

\section{The Association of Post-Concussion and Post-Traumatic Stress Disorder Symptoms with Health-Related Quality of Life, Health Care Use and Return-to-Work after Mild Traumatic Brain Injury}

\author{
Marjolein van der Vlegel ${ }^{1, *(D)}$, Suzanne Polinder ${ }^{1}$, Ana Mikolic ${ }^{1}$, Rana Kaplan ${ }^{1}$, Nicole von Steinbuechel ${ }^{2}$, \\ Anne Marie Plass ${ }^{2}$, Marina Zeldovich ${ }^{2}$ (D), Dominique van Praag ${ }^{3}$ (D), Fabian Bockhop ${ }^{2}$, Katrin Cunitz ${ }^{2}$, \\ Isabelle Mueller $^{2}$ (D) Juanita A. Haagsma ${ }^{1}$ and The CENTER-TBI Participants and Investigators ${ }^{\dagger}$ \\ check for \\ updates \\ Citation: van der Vlegel, M.; \\ Polinder, S.; Mikolic, A.; Kaplan, R.; \\ von Steinbuechel, N.; Plass, A.M.; \\ 1 Department of Public Health, Erasmus MC, 3000 CA Rotterdam, The Netherlands; \\ s.polinder@erasmusmc.nl (S.P.); a.mikolic@erasmusmc.nl (A.M.); z.kaplan@erasmusmc.nl (R.K.); \\ j.haagsma@erasmusmc.nl (J.A.H.) \\ 2 Institute of Medical Psychology and Medical Sociology, University Medical Center Göttingen (UMG), \\ Georg-August-University, 37073 Göttingen, Germany; nvsteinbuechel@med.uni-goettingen.de (N.v.S.); \\ annemarie.plass@med.uni-goettingen.de (A.M.P.); marina.zeldovich@med.uni-goettingen.de (M.Z.); \\ fabian.bockhop@med.uni-goettingen.de (F.B.); katrin.cunitz@med.uni-goettingen.de (K.C.); \\ isabelle.mueller@med.uni-goettingen.de (I.M.) \\ 3 Department of Psychology, Antwerp University Hospital, University of Antwerp, 2650 Edegem, Belgium; \\ Dominique.VanPraag@uza.be \\ * Correspondence: m.vandervlegel@erasmusmc.nl \\ + The list of CENTER-TBI Participants and Investigators is provided in the Supplementary Materials.
} Zeldovich, M.; van Praag, D.; Bockhop, F.; Cunitz, K.; et al. The Association of Post-Concussion and Post-Traumatic Stress Disorder Symptoms with Health-Related Quality of Life, Health Care Use and Return-to-Work after Mild Traumatic Brain Injury. J. Clin. Med. 2021, 10, 2473. https://doi.org/10.3390/ jcm10112473

Academic Editor: Morgan Brogg

Received: 30 April 2021

Accepted: 1 June 2021

Published: 2 June 2021

Publisher's Note: MDPI stays neutra with regard to jurisdictional claims in published maps and institutional affiliations.

Copyright: (C) 2021 by the authors. Licensee MDPI, Basel, Switzerland. This article is an open access article distributed under the terms and conditions of the Creative Commons Attribution (CC BY) license (https:// creativecommons.org/licenses/by/ $4.0 /)$
Abstract: Patients with mild traumatic brain injury (mTBI) are at risk for post-concussion (PC) symptoms and post-traumatic stress disorder (PTSD). The co-occurrence of PC and PTSD symptoms after mTBI in relation to health-related quality of life (HRQoL), health care utilization, and return to work has not yet been investigated. PC and PTSD symptoms were measured six months post-TBI by respectively the Rivermead Post-Concussion Symptoms Questionnaire (RPQ) and the Post-Traumatic Stress Disorder Checklist for DSM-5 (PCL-5). Of the 1566 individuals after mTBI who met the inclusion criteria, 26.1\% experienced PC symptoms (RPQ $\geq 16$ ). Additionally, 9.8\% experienced PTSD symptoms (PCL-5 $\geq 33$ ), of which the vast majority $(81 \%)$ also reported experiencing PC symptoms. Differences between patients with no/mild symptoms, with only PC, only PTSD, and both PC and PTSD symptoms in HRQoL, return to work, and rehabilitation were analyzed using logistic and linear regression analyses. Patients with PC and/or PTSD symptoms reported lower HRQoL, higher rates of rehabilitation, and lower return to work rates compared to patients with no/mild symptoms. Patients with both PC and PTSD symptoms reported significantly lower HRQoL $(\mathrm{B}=-2.73, \mathrm{CI}=-4.65 ;-0.83, p<0.001)$ compared to those with only PC symptoms, while there were no significant differences in their ongoing rehabilitation care $(\mathrm{OR}=1.39, \mathrm{CI}=0.77-2.49, p=0.272)$ and return to work rates $(\mathrm{OR}=0.49, \mathrm{CI}=0.15-1.63, p=0.246)$ at six months. These results underline the importance of the diagnosis and appropriate treatment of patients with mTBI, experiencing PC and/or PTSD symptoms.

Keywords: traumatic brain injury (TBI); post-concussion symptoms; Rivermead Post-Concussion Symptoms Questionnaire (RPQ); post-traumatic stress disorder; health-related quality of life; TBI outcome

\section{Introduction}

Traumatic brain injury (TBI) is an important public health problem with more than 50 million yearly cases worldwide [1]. It can be defined as 'an alteration in brain function, 
or other evidence of brain pathology, caused by an external force' [2]. The vast majority $(70-90 \%)$ of patients are classified as having mild TBI (mTBI) [1]. Individuals after mTBI may experience short and long-term physical, psychiatric, emotional, and cognitive disabilities $[3,4]$.

Patients with mTBI can suffer from various post-concussion (PC) symptoms and in some cases, these symptoms can persist for months [5-8]. PC symptoms can manifest as somatic problems (e.g., fatigue, headache, blurred vision), cognitive deficits (e.g., poor concentration, memory difficulty), or emotional and/or behavioral problems (e.g., depression, frustration, restlessness). Patients may also suffer from symptoms of posttraumatic stress disorder (PTSD) [6,9]. After mild TBI in the civilian setting, approximately $14 \%$ have PTSD [10]. These symptoms can be differentiated into four symptom groups: intrusion/re-experiencing, avoidance, negative alterations in cognition and mood, and increased arousal/reactivity. A clinical diagnosis of PTSD requires the presence of symptoms of all four groups [11,12]. Conceptually, there is an overlap between PC and PTSD symptoms due to similarities between PC symptoms and symptoms associated with the hyperarousal dimension of PTSD (e.g., concentration problems, sleep disturbances) [13,14]. As a result of the overlapping symptoms, some previous studies suggested that PC symptoms should be considered part of the arousal/reactivity subscale of PTSD [13]. However, it is also suggested that there is not only an overlap between post-concussion and PTSD symptoms but a possible interaction [15]. PTSD symptoms could exacerbate PC symptoms, and conversely, PC symptoms could prolong PTSD symptoms.

Experiencing long-term PC and PTSD symptoms after TBI can impair the working ability and the health-related quality of life (HRQoL) of a person [16,17]. Previous literature on patients with mTBI found that $76 \%$ of patients reported full return to work six months after injury [18]. Nevertheless, the association between PC and PTSD symptoms with return to work is still unknown. Previous studies have shown that patients with mTBI with PC or PTSD symptoms perceive a lower HRQoL compared to those without these symptoms [16,17,19-21]. However, the impact of the co-occurrence of PC and PTSD symptoms on HRQoL, health care utilization, and return to work has to our knowledge not yet been investigated. We hypothesize that patients who report both PC and PTSD symptoms have a lower HRQoL, higher health care utilization, and lower return to work rates. The aim of this study was to investigate the association of PC and PTSD symptoms with HRQoL, health care utilization, and return to work in patients with mTBI.

\section{Materials and Methods}

\subsection{Study Design and Population}

This study was part of the prospective multi-center longitudinal observational Collaborative European NeuroTrauma Effectiveness Research in Traumatic Brain Injury (CENTERTBI study, registered at ClinicalTrials.gov NCT02210221) [22]. Data were collected from December 2014 to December 2017 in 63 centers in Europe and Israel. Inclusion criteria were a clinical diagnosis of TBI, with an indication for computed tomography (CT) scanning, and presentation to a center within $24 \mathrm{~h}$ after injury [22,23]. Patients with a severe pre-existing neurological disorder i.e., cerebrovascular accident, transient ischemic attacks, and epilepsy, which could confound outcome assessments, were excluded. Three strata were used to prospectively differentiate patients by care pathways: emergency room (ER) (discharged after ER visit), admission (primarily admitted to hospital ward), and intensive care unit (ICU) (primarily admitted to ICU). Informed consent was obtained according to local regulations and the Medical Ethics Committees approved the CENTER-TBI study in all participating centers. The main descriptive findings of CENTER-TBI have been previously described [22,23]. In the current study, patients aged 16 years and older, with Glasgow Coma Scale (GCS) 13-15, who completed the Rivermead Post-Concussion Symptoms Questionnaire (RPQ) [24] and the Post-Traumatic Stress Disorder Checklist for the DSM-5 (PCL-5) [25] at six-month follow-up were included. 


\subsection{Measures}

\subsubsection{Sociodemographic Data}

Sex, age, (highest) educational level (primary school, secondary school, post-high school training, college/university), and employment status (full-time employed, part-time employed, unemployed, student, homemaker, retired) were assessed at time of enrollment in the study.

\subsubsection{Medical History}

Medical history was assessed at time of study enrollment. Pre-injury psychiatric medical history included sleep disorders, depression, anxiety, schizophrenia, drug abuse, or other psychiatric problems as reported by patients.

\subsubsection{Injury Characteristics}

Overall injury severity was rated by the Injury Severity Score (ISS), which ranges from 0 to 75 . It is calculated as the sum of square of the three highest values of the Abbreviated Injury Scale Score (AIS) from different body regions [26]. TBI severity was rated using the Glasgow Coma Scale (GCS) [27]. Participants with a baseline GCS score between 13 and 15 were classified as mild TBI and included in this study.

\subsubsection{Functional Outcome at Six Months Post-TBI}

Functional outcome was assessed at six months post-TBI using the Glasgow Outcome Scale Extended (GOSE). The GOSE differentiates eight outcome categories: dead (1), vegetative state (2), lower severe disability (3), upper severe disability (4), lower moderate disability (5), upper moderate disability (6), lower good recovery (7), and upper good recovery (8). The categories vegetative state and lower severe disability were combined as responses by postal questionnaire did not permit this differentiation. The GOSE score was dichotomized into incomplete recovery $(\mathrm{GOSE}<8)$ vs. full recovery $(\mathrm{GOSE}=8)$.

\subsubsection{Post-Concussion Symptoms at Six Months Post-TBI}

Post-concussion symptoms were assessed through the Rivermead Post-Concussion Symptoms Questionnaire (RPQ), which evaluates the frequency and severity of 16 symptoms including headaches, dizziness, nausea/vomiting, noise sensitivity, sleep disturbance, fatigue, being irritable, feeling depressed or tearful, feeling frustrated, or impatient, forgetfulness, poor concentration, taking longer to think, blurred vision, light sensitivity, double vision, and restlessness [24]. For each symptom, patients could respond on a five-point Likert scale ("not experienced at all", (1) "no more of a problem than before the TBI", (2) "a mild problem", (3) "a moderate problem", and (4) "a severe problem"). For the calculation of the total score, ratings from the 16 items were summed up, excluding the ratings of 1 ("no more of a problem than before") [24]. The total score ranges from 0 (representing no change in symptoms since TBI) to 64 (most severe symptoms). A total score $\geq 16$ was considered indicative of having severe PC symptoms [28].

\subsubsection{Post-Traumatic Stress Symptoms at Six Months Post-TBI}

Post-traumatic stress disorder symptoms were assessed with the PCL-5 [25]. The PCL-5 includes 20 items reflecting the DSM-5 diagnostic criteria of PTSD [29]. The items can be divided into four subscales: intrusion (five items), avoidance (two items), negative alterations in cognitions and mood (seven items), and alterations in arousal and reactivity (six items). The self-report rating scale ranges from 0 (not at all) to 4 (extremely) for each symptom and the sum of scores ranges from 0 to 80 . A total score $\geq 33$ is considered clinically relevant and was used to screen for PTSD in this study [30]. When referring to patients with PTSD in this study, this classification is solely based on an individual's PCL-5 score $\geq 33$. Formal diagnosis requires evaluation by a psychiatrist. 


\subsubsection{Health Care Utilization}

Data on hospital and ICU admission, length of hospital stay, length of ICU stay, and inpatient rehabilitation were collected. Both inpatient and outpatient rehabilitation were additionally assessed by a patient-reported questionnaire at 6-months follow-up. Inpatient rehabilitation included admission to a general, TBI specialized, geriatric, psychiatric rehabilitation or nursing home unit. Outpatient rehabilitation included physical therapy, occupational therapy, speech therapy, therapeutic recreation, cognitive remediation, vocational services, psychological services, nursing services, comprehensive day treatment, peer mentoring, social work, independent living, and home health.

\subsubsection{Return to Work at Six Months Post-TBI}

Return to work was assessed at six-month follow-up. Participants were categorized into three groups: (1) return to work at full level (returned to previous job at same or increased level/hours, change of job), (2) return to work at reduced level/hours (return to previous job at reduced level/hours, sheltered employment), or (3) no return to work (unable to work, looking for work). For return to work, we included employed participants under the age of 65 years in the analyses.

\subsubsection{Health Related Quality of Life at Six Months Post-TBI}

Generic HRQoL was assessed using the 12-item Short Form Health Survey-Version 2 (SF-12v2) [31]. The HRQoL is summarized as a mental component score (MCS) and a physical component score (PCS), which ranges from 0 to 100. If there was no available SF-12v2 score, the score was derived using the long version of the questionnaire (i.e., the SF-36v2) if available [23]. Scores $<40$ are considered to reflect impaired HRQoL [32].

The six-item Quality of Life after Brain Injury Overall Scale (QOLIBRI-OS) is a TBIspecific instrument measuring HRQoL [33]. The instrument assesses the overall satisfaction with life (physical condition, cognition, emotions, function in daily life, personal and social life, and current situation and future prospects). The total score is calculated by computing the mean for the six items and converting this to a percent score by subtracting one and multiplying by 25 . The scale can range from 0 to 100 , and scores $<52$ are considered to reflect impaired HRQoL [32].

\subsection{Ethical Approval}

The CENTER-TBI study has been conducted in accordance with all relevant laws of the EU if directly applicable or of direct effect, and all relevant laws of the country where the recruiting sites were located, including, but not limited to, the relevant privacy and data protection laws and regulations (the "Privacy Law"), the relevant laws and regulations on the use of human materials, and all relevant guidance relating to clinical studies from time to time in force including, but not limited to, the ICH Harmonized Tripartite Guideline for Good Clinical Practice (CPMP/ICH/135/95) ("ICH GCP") and the World Medical Association Declaration of Helsinki entitled "Ethical Principles for Medical Research Involving Human Subjects". Ethical approval was obtained for each recruiting site. Informed consent was obtained for all patients recruited in the Core Dataset of CENTER-TBI and documented in the e-CRF. The list of sites, ethical committees, approval numbers, and approval dates can be found on the official Center TBI website (www.center-tbi.eu/project/ethical-approval, accessed on 30 April 2021).

\subsection{Statistical Analysis}

Data were extracted from the INCF Neurobot tool version 3.0 (INCF, Solna, Sweden), which is a clinical study data management tool. Descriptive statistics were reported for patient and injury characteristics, and outcome variables. Continuous variables were described with mean and standard deviation (SD) or median and interquartile range (IQR) and categorical data were described with frequencies. 
Four groups of patients with and without severe PC and PTSD symptoms were created. Patients were categorized into one of four groups based on RPQ and PCL-5 scores: (1) no/mild symptoms: RPQ < 16 and PCL-5 < 33, (2) PC symptoms: RPQ $\geq 16$ and PCL-5 <33, (3) PC and PTSD symptoms: RPQ $\geq 16$ and PCL-5 $\geq 33$, (4) PTSD symptoms: $R P Q<16$ and PCL-5 $\geq 33$. To analyze group differences, the Kruskal-Wallis test for continuous variables and chi-square test for contingency tables for categorical variables were used.

To evaluate the correlation between the RPQ and PCL- 5 subscales, Spearman's correlation coefficients were utilized. A correlation was considered strong when the coefficient was $\geq 0.5$, moderate when the coefficient was between 0.3 and 0.5 , and weak when the coefficient was below 0.3 [34].

Multivariate imputation by chained equations was used to impute missing values in potential confounders. All baseline variables, RPQ, PCL-5, SF-12, QoLIBRI-OS, hospital and ICU admission, and rehabilitation care were included in the imputation model. Outcome variables were not imputed. To explore the association between the symptom groups and HRQoL six months post-TBI, multivariable linear regression analyses were performed. Logistic regression analyses were applied to estimate the association between symptom groups and six-month outpatient rehabilitation as well as between symptom groups and return to work at pre-injury level six-months post-TBI. The assumptions of the linear and logistic regression models were met. Additionally, HRQoL of patients with and without ongoing outpatient rehabilitation care and of patients who returned to work versus not returned to work were reported for each symptom group.

For all analyses, a $p$-value of $p<0.05$ was considered significant. All statistical analyses were performed using SPSS version 25 for Windows (IBM SPSS Statistics, SPSS Inc, Chicago, IL, USA) and R (version 3.5, the R Foundation for Statistical Computing, Vienna, Austria), using the mice package for imputation of missing values.

\section{Results}

\subsection{Patient Characterstics}

In total, 4509 patients were recruited into the CENTER-TBI study. Of patients $\geq$ 16 years after mTBI $(n=2864), 1566$ provided information on PC and PTSD symptoms six months post TBI and were included in this study (Figure 1). As shown in Figure 1, $26.1 \%(n=408)$ of the participants reported severe PC symptoms and $9.8 \%(n=153)$ of the participants suffered from clinically relevant PTSD symptoms. A total of $7.9 \%(n=124)$ of participants met the criteria of both severe PC and clinically relevant PTSD. Baseline characteristics and outcome data are reported in Table 1, which were differentiated for the presence or absence of PC and PTSD symptoms (Table 1). Patients that met the criteria for PTSD were younger and more often had a history of psychiatric problems than those who did not. Patients with severe PC symptoms were more often admitted to the ICU (37.0\%) and had the highest ISS (median 13.0) compared to the other groups. At the six-month follow-up, $60.1 \%$ of patients with no/mild symptoms had good recovery (GOSE score 8 ) compared to $13.4 \%$ of patients with only severe PC symptoms, $16.1 \%$ of patients with severe PC and PTSD symptoms, and $27.6 \%$ of patients with only PTSD symptoms $(p<0.001)$. 
Table 1. Descriptive statistics of the total sample and for patients with severe PC and/or PTSD symptoms, at six months post-mTBI.

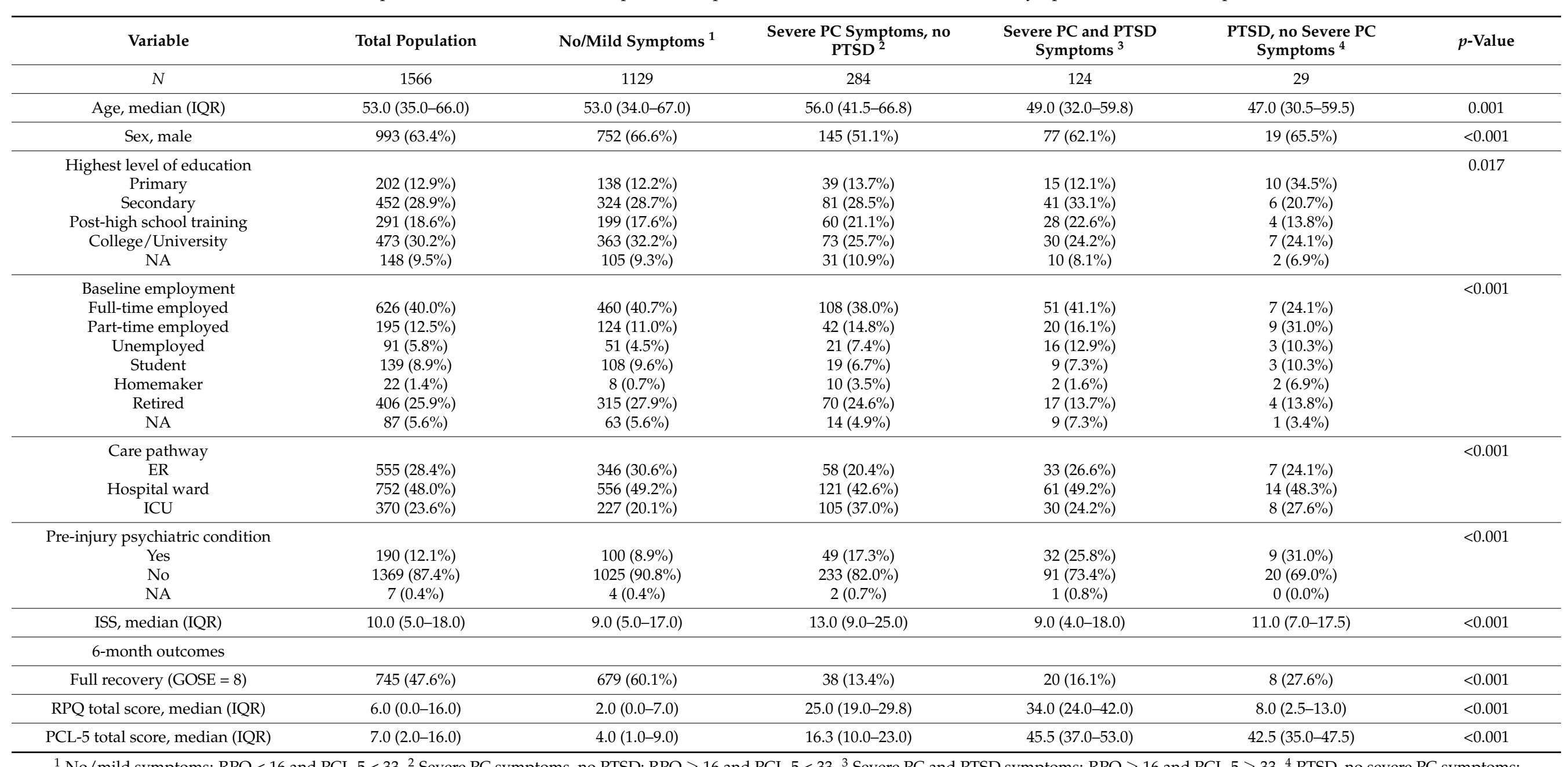

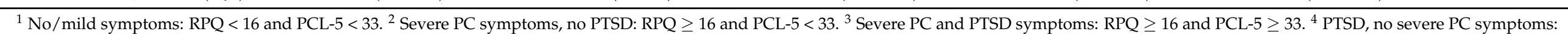

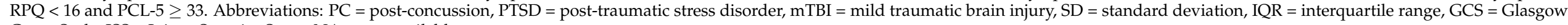
Coma Scale, ISS = Injury Severity Score, NA = not available 


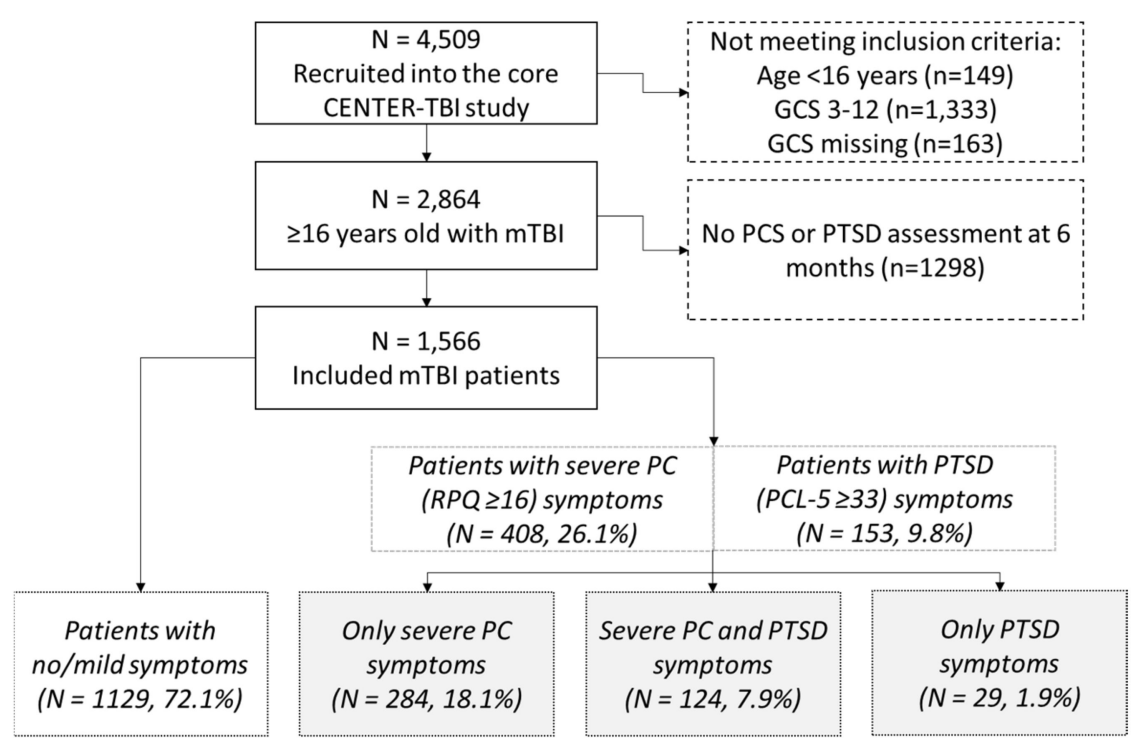

Figure 1. Flow chart. $n=$ number; $\mathrm{mTBI}=$ mild traumatic brain injury; $\mathrm{PCS}=$ post-concussion symptoms; PTSD = post-traumatic stress disorder.

\subsection{Prevalence of Post-Concussion and Post-Traumatic Stress Disorder Symptoms}

Six months after TBI, fatigue was the most frequently reported post-concussion symptom (42.1\%), followed by 'forgetfulness' (36.1\%) and 'poor concentration' (33.3\%) (Figure A1, Appendix A). The most frequently reported PTSD symptoms were 'difficulty concentrating' (51.1\%), 'trouble with sleep' (49.1\%), and 'trouble remembering' (46.1\%) (Figure A2, Appendix A). 'Light sensitivity' (15.4\%), 'double vision' (8.0\%), and 'nausea' $(7.2 \%)$ were the least frequently reported post-concussion symptoms and 'strong physical reactions' $(21.8 \%)$, 'distressing dreams' $(19.4 \%)$, and 'risk taking' $(18.9 \%)$ were the least frequently reported PTSD symptoms. Figure 2 shows the Spearman's correlation coefficients between RPQ symptoms and PCL-5 subscales. A strong correlation was observed between severity of PTSD symptoms in the arousal/reactivity PCL-5 subscale and the majority of RPQ symptoms. The strongest correlations were with 'poor concentration' (0.649), 'frustration' (0.628), and 'irritability' (0.622). Severity of the cognition and mood symptoms PCL-5 subscale had strong correlations with 'feeling depressed' (0.553), 'frustration' (0.545), 'poor concentration' (0.522), and 'irritability' (0.516). The correlations between the intrusion and avoidance PCL-5 subscales, and RPQ symptoms were moderate to weak. The total scores of the RPQ showed a positive correlation with the total scores of the PCL-5 ( $r=0.706$, $p<0.001$ ) (Figure A3, Appendix A).

3.3. Differences in HRQoL, Health Care Utilization, and Return to Work among the Severe PC and PTSD Groups

Patients with severe PC and/or PTSD symptoms at six months post TBI reported lower HRQoL scores than patients with no/mild symptoms, with lowest scores for patients with both severe PC and PTSD symptoms (Table 2). After adjustment for age, sex, educational level, psychiatric history, and ISS, patients with severe PC and PTSD symptoms had significantly lower HRQoL scores than patients with only severe PC symptoms, based on SF-12 physical component score (B $-2.73,95 \%$ CI $-4.64 ;-0.83, p=0.001)$, SF-12 mental component score (B -9.37, 95\% CI - 11.28; $-7.46, p<0.001)$, and QoLIBRI-OS (B - 11.87, $95 \%$ CI $-15.49 ;-8.24, p<0.001$ ) (Table A1, Appendix B). 


\begin{tabular}{|c|c|c|c|}
\hline RPQ symptom & 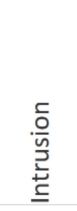 & 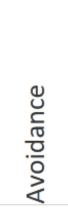 & 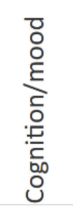 \\
\hline Headache & 0.340 & 0.290 & 0.337 \\
\hline Dizziness & 0.310 & 0.290 & 0.327 \\
\hline Nausea & 0.260 & 0.230 & 0.269 \\
\hline Noise Sensitivity & 0.360 & 0.320 & 0.386 \\
\hline Sleep Disturbance & 0.370 & 0.290 & 0.415 \\
\hline Fatigue & 0.370 & 0.320 & 0.458 \\
\hline Irritable & 0.410 & 0.325 & 0.516 \\
\hline Depressed & 0.490 & 0.393 & 0.553 \\
\hline Frustrated & 0.410 & 0.350 & 0.545 \\
\hline Forgetfulness & 0.360 & 0.317 & 0.461 \\
\hline Poor Concentration & 0.410 & 0.347 & 0.522 \\
\hline Taking Longer To Think & 0.370 & 0.338 & 0.459 \\
\hline Blurred Vision & 0.300 & 0.265 & 0.321 \\
\hline Light Sensitivity & 0.310 & 0.286 & 0.329 \\
\hline Double Vision & 0.260 & 0.216 & 0.246 \\
\hline Restlessness & 0.400 & 0.337 & 0.459 \\
\hline
\end{tabular}

Figure 2. Spearman rank correlations between RPQ symptoms and PCL-5 subscales. All correlations were statistically significant. RPQ: Rivermead Post-Concussion Symptoms Questionnaire; PCL-5: Post-Traumatic Stress Disorder Checklist for the DSM-5.

Table 2. Health-related quality of life by PC and PTSD symptom status, 6 months post-TBI.

\begin{tabular}{ccccc}
\hline $\begin{array}{c}\text { HRQoL } \\
\text { Measure }\end{array}$ & $\begin{array}{c}\text { No/Mild } \\
\text { Symptoms }\end{array}$ & $\begin{array}{c}\text { Severe PC Symptoms, } \\
\text { No PTSD }\end{array}$ & $\begin{array}{c}\text { Severe PC and } \\
\text { PTSD Symptoms }\end{array}$ & $\begin{array}{c}\text { PTSD, No Severe } \\
\text { PC Symptoms }^{\mathbf{4}}\end{array}$ \\
\hline Participants & $n=1129$ & $n=284$ & $n=124$ & $n=29$ \\
\hline SF-12 PCS & $48.9 *(9.3)$ & $40.2(11.1)$ & $39.2 *(10.7)$ & $47.3 *(10.6)$ \\
\hline SF-12 MCS & $52.0 *(8.7)$ & $41.3(10.2)$ & $31.6 *(9.6)$ & $36.9 *(8.9)$ \\
\hline QoLIBRI-OS & $77.1 *(16.6)$ & $54.5(18.6)$ & $42.3 *(21.5)$ & $52.6(21.3)$ \\
\hline
\end{tabular}

${ }^{*}$ Linear regression analysis on HRQoL at 6 months. Statistically significant $(p<0.05)$ difference compared to the 'only PC group' after adjusted for age, sex, educational level, psychiatric history, and injury severity score. ${ }^{1}$ No/mild symptoms: RPQ $<16$ and PCL- $5<33$. ${ }^{2}$ Severe PC symptoms, no PTSD: RPQ $\geq 16$ and PCL-5 $<33$ ${ }^{3}$ Severe PC and PTSD symptoms: RPQ $\geq 16$ and PCL-5 $\geq 33 .{ }^{4}$ PTSD, no severe PC symptoms: RPQ $<16$ and PCL-5 $\geq 33$. Abbreviations: $\mathrm{PC}=$ post-concussion, $\mathrm{PTSD}=$ post-traumatic stress disorder, $\mathrm{HRQ}$ RL $=$ health-related quality of life, SF-12 PCS = 12-item Short Form Health Survey-Version 2 physical component score, SF-12 PCS = 12-item Short Form Health Survey-Version 2 mental component score, QoLIBRI-OS = Quality of Life after Brain Injury Overall Scale. 
Patients with severe PC and/or PTSD symptoms at six months post TBI were more likely to have been admitted to a hospital ward or ICU and to receive inpatient and outpatient rehabilitation care after sustaining their TBI compared to patients not meeting criteria for severe PC and PTSD symptoms (Table 3). After adjustment for age, sex, educational level, psychiatric history, and ISS, there were no significant differences in hospital and ICU admission or inpatient rehabilitation between groups, with the exception of a higher likelihood of ICU admission after TBI for patients with severe PC symptoms compared to patients no/mild symptoms (OR $0.54, \mathrm{CI} 0.36-0.81, p=0.003$ ) and patients with severe PC and PTSD symptoms (OR 0.42, CI 0.20-0.84, $p=0.015$ ) (Table A2, Appendix B). For outpatient rehabilitation, there was no significant difference in the likelihood of receiving ongoing rehabilitation care after six months for patients with severe PC symptoms compared to patients with both severe PC and PTSD symptoms (OR 1.39, CI 0.77-2.49, $p=0.272$ ). For patients with severe PC and/or PTSD symptoms, HRQoL was comparable to patients who did and did not receive rehabilitation care at six months (Table A3, Appendix B). However, patients not meeting criteria for severe PC and PTSD symptoms, who received care at six months reported significantly lower HRQoL compared to those who did not. Additionally, those patients with ongoing rehabilitation care at six months had higher ISS in each group compared to those not receiving rehabilitation care after six months (Table A4, Appendix B).

Table 3. Health care utilization by PC and PTSD symptom status.

\begin{tabular}{ccccc}
\hline Health Care Utilization & $\begin{array}{c}\text { No/Mild } \\
\text { Symptoms }\end{array}$ & $\begin{array}{c}\text { Severe PC Symptoms, } \\
\text { No PTSD }{ }^{2}\end{array}$ & $\begin{array}{c}\text { Severe PC and PTSD } \\
\text { Symptoms }{ }^{3}\end{array}$ & $\begin{array}{c}\text { PTSD, No Severe PC } \\
\text { Symptoms }\end{array}$ \\
\hline Participants & $n=1129$ & $n=284$ & $n=124$ & $n=29$ \\
\hline In-hospital & & & & \\
Admission at hospital ward & $67.6 \%$ & $74.8 \%$ & $67.7 \%$ & $79.3 \%$ \\
Hospital length of stay in days ${ }^{4}$ & $5.7(10.6)$ & $6.8(9.1)$ & $8.6(11.5)$ & $7.3(8.6)$ \\
Admission at ICU & $21.0 \% *$ & $37.9 \%$ & $24.2 \%{ }^{*}$ & $27.6 \%$ \\
ICU length of stay in days ${ }^{*}$ & $5.0(7.4)$ & $4.9(7.6)$ & $8.7(10.9)$ & $5.6(6.4)$ \\
\hline Inpatient rehabilitation & $10.9 \%$ & $17.4 \%$ & $13.7 \%$ & $17.2 \%$ \\
\hline Outpatient rehabilitation & $15.7 \% *$ & $31.2 \%$ & $30.9 \%$ & $19 \%$ \\
Ongoing after six months ${ }^{*}$ & $6.5 \%$ & $18.4 \%$ & $24.1 \%$ & $6.9 \%$ \\
\hline
\end{tabular}

* Logistic regression analysis on health care utilization. Statistically significant $(p<0.05)$ difference compared to the 'only PC group' after adjusted for age, sex, educational level, psychiatric history, and Injury Severity Score. ${ }^{1} \mathrm{No} / \mathrm{mild}$ symptoms: RPQ $<16$ and PCL-5 $<33$. ${ }^{2}$ Severe PC symptoms, no PTSD: RPQ $\geq 16$ and PCL-5 $<33 .{ }^{3}$ Severe PC and PTSD symptoms: RPQ $\geq 16$ and PCL-5 $\geq 33 .{ }^{4}$ PTSD, no severe PC symptoms: RPQ $<16$ and PCL-5 $\geq 33 .{ }^{5}$ Mean (SD) number of days for those admitted. ${ }^{6}$ Percentage of patients that received ongoing outpatient rehabilitation six months after TBI. Abbreviations: PC $=$ post concussion, PTSD $=$ post-traumatic stress disorder, ICU = intensive care unit.

Table 4 shows the proportion of patients that returned to work within six months postTBI. There were 760 employed participants aged $16-65$ years. While $83.2 \%$ of patients with no/mild symptoms returned to work at pre-injury level at six months after TBI, patients with severe PC symptoms, PTSD symptoms, or both severe PC and PTSD symptoms had return-to-work rates of respectively $46.1 \%, 62.5 \%$, and $59.0 \%$. After adjustment for age, sex, educational level, psychiatric history, and ISS, return to work rates did not differ significantly between patients with only severe PC symptoms and patients with both PC and PTSD symptoms (OR $0.82,95 \%$ CI: $0.42-1.63, p=0.595$ ) or only PTSD symptoms (OR 0.49, 95\% CI: 0.15-1.63, $p=0.246$ ) (Table A5, Appendix B). Within each group, SF-12 physical component scores were significantly lower for those who reported no full return to work within six months, while SF-12 mental component scores were comparable for patients with and without return to work. Additionally, patients with severe PC and/or PTSD symptoms who returned to work reported higher SF-12 physical component scores than patients with no/mild symptoms who did not return to work (Table A6, Appendix B). The ISS of patients not returning to work at six months was higher compared to those that did return to work. The ISS of patients with no/mild symptoms who did not return to 
work within six months was twice as high (mean 22.1, SD 15.0) than for patients who did return to work at full level (mean 11.3, SD 8.8) ( $p<0.001$ ) (Table A7, Appendix B).

Table 4. Return to work at 6 months post TBI by PC and PTSD symptoms status.

\begin{tabular}{|c|c|c|c|c|c|}
\hline Return to Work & Total Population & $\begin{array}{c}\text { No/Mild } \\
\text { Symptoms }\end{array}$ & $\begin{array}{c}\text { Severe PC } \\
\text { Symptoms, No } \\
\text { PTSD }^{2}\end{array}$ & $\begin{array}{c}\text { Severe PC and } \\
\text { PTSD Symptoms }\end{array}$ & $\begin{array}{l}\text { PTSD, No Severe } \\
\text { PC Symptoms }\end{array}$ \\
\hline Participants & $n=1566$ & $n=1129$ & $n=284$ & $n=124$ & $n=29$ \\
\hline $\begin{array}{l}\text { Pre-TBI employed } \\
\text { participants }{ }^{5}\end{array}$ & $n=760(48.5 \%)$ & $n=540(47.8 \%)$ & $n=138(48.6 \%)$ & $n=66(53.2 \%)$ & $n=16(55.2 \%)$ \\
\hline $\begin{array}{l}\text { Return to work at } \\
\text { full level }\end{array}$ & $74.3 \%$ & $83.2 \%$ * & $46.1 \%$ & $59.0 \%$ & $62.5 \%$ \\
\hline $\begin{array}{l}\text { Return to work at } \\
\text { reduced level/hours }\end{array}$ & $9.5 \%$ & $8.0 \%$ & $17.2 \%$ & $8.2 \%$ & $0.0 \%$ \\
\hline No return to work & $16.2 \%$ & $8.8 \%$ & $36.7 \%$ & $32.8 \%$ & $37.5 \%$ \\
\hline
\end{tabular}

${ }^{*}$ Logistic regression analysis on 6-month return to work at full level. Statistically significant $(p<0.05)$ difference compared to the 'only PC group' after adjusted for age, sex, educational level, psychiatric history, and Injury Severity Score. ${ }^{1} \mathrm{No} / \mathrm{mild}$ symptoms: RPQ $<16$ and PCL-5 < 33. ${ }^{2}$ Severe PC symptoms, no PTSD: RPQ $\geq 16$ and PCL-5 < 33. ${ }^{3}$ Severe PC and PTSD symptoms: RPQ $\geq 16$ and PCL-5 $\geq 33$. ${ }^{4}$ PTSD, no severe PC symptoms: RPQ $<16$ and PCL-5 $\geq 33 .{ }^{5} 20$ missing values $(2.6 \%)$. Abbreviations: $\mathrm{PC}=$ post-concussion, $\mathrm{PTSD}=$ post-traumatic stress disorder.

\section{Discussion}

This study aimed to investigate the co-occurrence of PC and PTSD symptoms in patients with mTBI and the association of these symptoms with HRQoL, health care utilization, and return to work. Six months after mTBI, one in four patients experienced severe PC symptoms. Furthermore, nearly $10 \%$ experienced symptoms indicative of PTSD, of which the vast majority $(81 \%)$ also reported experiencing severe PC symptoms. The correlation between post-concussion symptoms and symptoms of the PTSD arousal/reactivity subscale was strong. Our study showed that severe PC and/or PTSD symptoms were associated with lower HRQoL, higher use of rehabilitation care, and lower return to work rates. We found that patients experiencing both PC and PTSD symptoms reported the lowest HRQoL, while use of rehabilitation care and return to work rates were comparable between patients with only PC symptoms and both severe PC and PTSD symptoms.

The correlation found between PC symptoms and symptoms of the PTSD arousal/reactivity subscale is in accordance with a previous study that also showed this correlation in mild TBI patients [13]. As a result of the high correlation between several PC and PTSD symptoms, in our study, most patients with probable PTSD also score higher on PC symptoms. Reversely, most patients with severe PC symptoms do not meet the criteria for PTSD apart from those with very high $R P Q$ scores. The overlapping symptoms complicate accurate attribution of the cause of these symptoms to a specific disorder. This has important implications for the treatment of the patient. Diagnosis of PTSD in persons six months after TBI might disguise the proper diagnosis of PC symptoms since the high PTSD scores might be due to the high PC symptom burden these people still experience. As a result of the large overlap in PC or PTSD symptoms and their co-occurrence in relationship with other outcomes, including HRQoL, long-term rehabilitation, and return to work, caution is warranted in linking disorders independently to adverse outcomes.

A previous systematic review on HRQoL in patients who sustained a TBI showed that in the long-term, patients still showed large deviations from full recovery when measured by population norms [35]. Our study showed substantial differences between patients with mTBI, with and without severe PC, and PTSD symptoms. Patients with no/mild symptoms had HRQoL scores comparable to population norms from several European countries, indicating that this group had good recovery $[36,37]$. Previous studies have reported on the association between PC symptoms or PTSD with lower HRQoL [16,17]. An important finding of our study is that severe PC and PTSD symptoms possibly intensify each other, since patients with combined symptoms had the lowest HRQoL. Another explanation for 
these low HRQoL scores could be the high severity of PC symptoms in the group with both severe PC and PTSD symptoms.

Our study showed that in total, $74.3 \%$ of patients with mTBI return to work at preinjury level, which is in accordance with previous literature [18,38]. However, our results did indicate significant differences between patients with and without PC and PTSD symptoms. Around half of all participants with severe PC and/or PTSD symptoms have not resumed work at a pre-injury level. These symptoms might affect physical, psychosocial, and cognitive skills, and therefore one's ability to work [39,40]. While patients with mTBI with no or mild symptoms after six months are expected to show good recovery, a subgroup of these patients still received rehabilitation care six months post TBI and did not return to work at that time. However, there may be other causes that prevent patients from full recovery. One explanation for this could be the presence of extra-cranial injury, since these patients showed physical HRQoL scores that were below population norms. Another explanation might be the higher ISS scores indicating multiple injuries, due to which the rehabilitation process lasts longer. Additionally, patients with severe PC symptoms had higher ISS than those without these symptoms, which might explain the lower HRQoL scores for this group. However, the presence of PC likely complicates recovery not just for organic reasons but for secondary psychological effects [41]. While early PC may be best described as a neurological problem, the chronic presence of PC likely includes the development of neuropsychiatric symptoms [42]. The typical symptoms of PC are difficult to treat and may encourage maladaptive coping methods, further complicating recovery. Moreover, the often associated loss of employment, social role, and overall HRQoL can be psychologically challenging and may increase the likelihood of emerging dysphoria, dysthymia, or depression, especially in patients with pre-existing risk factors for mood disorders [43]. The rise of these secondary psychiatric symptoms may further complicate a successful treatment of PC [44]. This underlines the complexity of the recovery after TBI.

\subsection{Strengths and Limitations}

In this study, a large dataset was used including patients from hospital centers across Europe. Previous studies focused exclusively on either post-concussion or PTSD symptoms in relation to other outcomes. Our study underlines the importance of measuring both, since HRQoL was lowest for patients experiencing both. That could suggest a possible interaction and mutual exacerbation of symptoms. However, the severity of PC symptoms in this group could be another explanation for these results.

There were some limitations to this study. First, patients were categorized in one of four groups based on self-reported RPQ and PCL-5 data. However, the use of these questionnaires is not sufficient to clinically diagnose patients with, for example, PTSD, where the gold standard is a (semi-)structured interview. Additionally, it is important to note that there is not one optimal RPQ and PCL- 5 cut-off, as previous studies recommended a variety of cut-off scores $[28,30,45,46]$. This lack of standardized cut-off points may have affected the magnitude of the odds ratio (OR) as well [47]. While OR is widely used as an indicator of risk for disease, it can vary strongly depending on sample size, case rates, and applied cut-off scores in data [48]. Furthermore, CENTER-TBI participants (see Supplementary Materials) were mainly recruited from trauma referral centers. This may be a selected sample of neurotrauma centers, limiting generalizability to all European TBI patients.

\subsection{Outlook}

Identification of patients with PC and/or PTSD symptoms and medical and psychological interventions for those specific patients might be effective in prevention of long-term post-concussion and PTSD symptoms. In turn, the need for long-term rehabilitation care might decrease and HRQoL and return-to-work rates might increase [49,50]. This is important, since half of the patients with symptoms did not return to their previous work level, causing a large burden for both the patient and society. Clinicians should not overlook a 
diagnosis of post-concussion when a patient also reports PTSD symptoms. Additionally, future prospective studies could clarify the possible causal relationship and interaction between PC and PTSD symptoms and their relationship with other outcomes. We conclude that there is a need for paying attention to the diagnosis of patients with mTBI, experiencing post-concussion and/or PTSD symptoms, to ensure appropriate interventions and to facilitate recovery.

Supplementary Materials: The following are available online at https:/ /www.mdpi.com/article/10 $.3390 / \mathrm{jcm} 10112473 / \mathrm{s} 1$, The list of CENTER-TBI participants and investigators.

Author Contributions: All authors have contributed substantially to the work reported. All authors critically revised the paper. Conceptualization, M.v.d.V., S.P., J.A.H.; Data curation, M.v.d.V., S.P., J.A.H., R.K.; Formal analysis, M.v.d.V.; Methodology, M.v.d.V., S.P., A.M., J.A.H.; Supervision, S.P., A.M.P., N.v.S., J.A.H.; Visualization, M.v.d.V.; Writing—original draft, M.v.d.V.; Writing—review and editing, M.v.d.V., S.P., A.M., R.K., N.v.S., A.M.P., M.Z., D.v.P., F.B., K.C., I.M., J.A.H. All authors have read and agreed to the published version of the manuscript.

Funding: CENTER-TBI was supported by the European Union 7th Framework program (EC grant 602150). Additional funding was obtained from the Hannelore Kohl Stiftung (Germany), from OneMind (USA), from Integra LifeSciences Corporation (USA) and from Neurotrauma Sciences (USA).

Institutional Review Board Statement: The CENTER-TBI study (EC grant 602150) has been conducted in accordance with all relevant laws of the European Union (EU) if directly applicable or of direct effect and all relevant laws of the country where the recruiting sites were located. Informed consent by the patients and/or the legal representative/next of kin was obtained, accordingly to the local legislations. For the full list of sites, ethical committees, and ethical approval details, see the official CENTER-TBI website (https:/ / www.center-tbi.eu/project/ethical-approval).

Informed Consent Statement: Informed consent was obtained from all subjects involved in the study.

Data Availability Statement: The data-sharing policy of CENTER-TBI can be found here: https: //www.center-tbi.eu/data/sharing (accessed on 30 April 2021).

Acknowledgments: The authors would like to thank all study participants and the CENTER-TBI investigators.

Conflicts of Interest: The authors declare no conflict of interest. The funders had no role in the design of the study; in the collection, analyses, or interpretation of data; in the writing of the manuscript, or in the decision to publish the results.

\section{Appendix A}

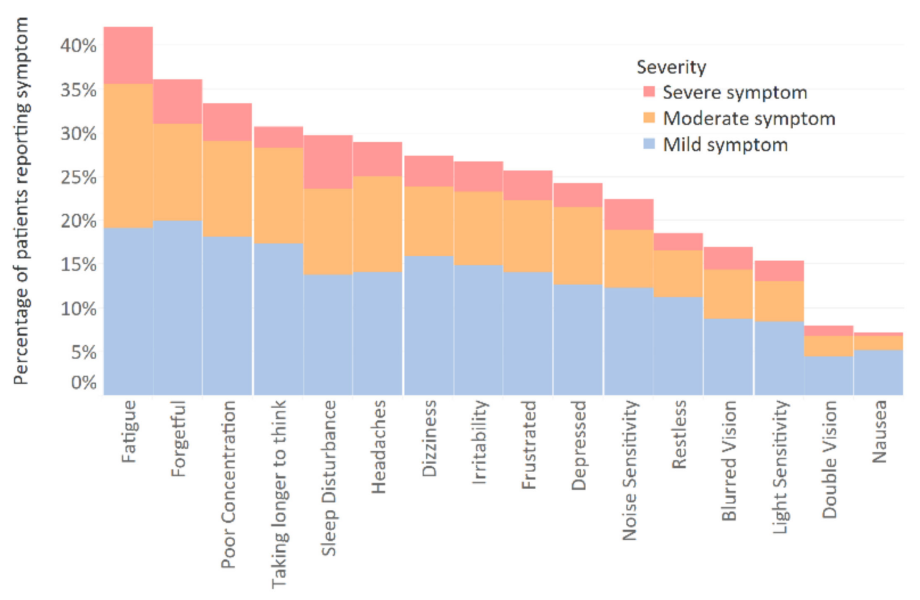

Figure A1. Frequency of post-concussion symptoms as measured by the RPQ 6 months post-TBI. 




Figure A2. Frequency of post-traumatic stress disorder symptoms as measured by the PCL-5 at 6 months post-TBI.

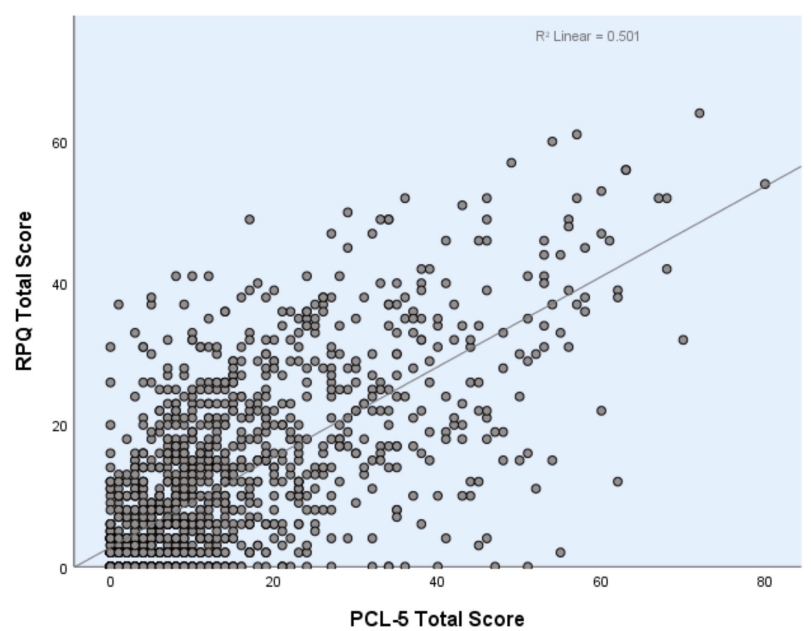

Figure A3. Regression line graph of RPQ total scores and PCL-5 total scores. RPQ: Rivermead PostConcussion Symptoms Questionnaire; PCL-5: Post-Traumatic Stress Disorder Checklist for the DSM-5.

\section{Appendix B}

Table A1. Linear regression analysis on HRQoL at 6 months.

\begin{tabular}{|c|c|c|c|c|c|c|}
\hline & \multicolumn{2}{|l|}{ SF-12 PCS } & \multicolumn{2}{|l|}{ SF-12 MCS } & \multicolumn{2}{|c|}{ QOLIBRI-OS Total Score } \\
\hline & B $(95 \% \mathrm{CI})$ & $p$-Value & B $(95 \% \mathrm{CI})$ & $p$-Value & B $(95 \% \mathrm{CI})$ & $p$-Value \\
\hline \multicolumn{7}{|l|}{ Unadjusted } \\
\hline $\begin{array}{c}\text { No/mild symptoms (ref PC } \\
\text { symptoms) }\end{array}$ & $8.77(7.49 ; 10.05)$ & $<0.001$ & $10.77(9.59 ; 11.96)$ & $<0.001$ & $22.28(20.01 ; 24.54)$ & $<0.001$ \\
\hline $\begin{array}{l}\text { Severe PC and PTSD symptoms } \\
\text { (ref PC symptoms) }\end{array}$ & $-0.94(-3.03 ; 1.14)$ & 0.374 & $-9.64(-11.56 ;-7.71)$ & $<0.001$ & $-11.13(-14.83 ;-7.42)$ & $<0.001$ \\
\hline $\begin{array}{c}\text { PTSD symptoms (ref PC } \\
\text { symptoms) }\end{array}$ & $7.12(3.38 ; 10.86)$ & $<0.001$ & $-4.37(-7.83 ;-0.91)$ & 0.013 & $-2.33(-8.90 ; 4.24)$ & 0.487 \\
\hline \multicolumn{7}{|l|}{ Adjusted $^{1}$} \\
\hline $\begin{array}{c}\text { No/mild symptoms (ref PC } \\
\text { symptoms) }\end{array}$ & $7.24(6.04 ; 8.43)$ & 0.005 & $10.03(8.83 ; 11.23)$ & $<0.001$ & $20.58(18.31 ; 22.84)$ & $<0.001$ \\
\hline $\begin{array}{l}\text { Severe PC and PTSD symptoms } \\
\text { (ref PC symptoms) }\end{array}$ & $-2.73(-4.64 ;-0.83)$ & 0.001 & $-9.37(-11.28 ;-7.46)$ & $<0.001$ & $-11.87(-15.49 ;-8.24)$ & $<0.001$ \\
\hline $\begin{array}{l}\text { PTSD symptoms (ref PC } \\
\text { symptoms) }\end{array}$ & $5.99(2.57 ; 9.41)$ & $<0.001$ & $-3.66(-7.10 ;-0.22)$ & 0.037 & $-1.60(-8.02 ;-4.82)$ & 0.625 \\
\hline
\end{tabular}

${ }^{1}$ Adjusted for age, sex, educational level, psychiatric history and injury severity score. Abbreviations: PC = post-concussion, PTSD = posttraumatic stress disorder, HRQoL = health-related quality of life, SF-12 PCS = 12-item Short Form Health Survey-Version 2 physical component score, SF-12 PCS = 12-item Short Form Health Survey-Version 2 mental component score, QoLIBRI-OS = Quality of Life after Brain Injury Overall Scale. 
Table A2. Logistic regression analysis on health care utilization.

\begin{tabular}{|c|c|c|c|c|c|c|c|c|c|c|c|c|}
\hline & \multicolumn{3}{|c|}{ Hospital Ward Admission } & \multicolumn{3}{|c|}{ ICU Admission } & \multicolumn{3}{|c|}{ Inpatient Rehabilitation } & \multicolumn{3}{|c|}{$\begin{array}{l}\text { Ongoing Outpatient } \\
\text { Rehabilitation }\end{array}$} \\
\hline & OR & CI (95\%) & $p$-Value & OR & CI (95\%) & $p$-Value & OR & CI (95\%) & $p$-Value & OR & CI (95\%) & $p$-Value \\
\hline \multicolumn{13}{|l|}{ Unadjusted } \\
\hline $\begin{array}{l}\text { No/mild symptoms (ref PC } \\
\text { symptoms) }\end{array}$ & 0.70 & $0.52-0.94$ & 0.019 & 0.44 & $0.33-0.58$ & $<0.001$ & 0.58 & $0.41-0.84$ & 0.003 & 0.31 & $0.21-0.45$ & $<0.001$ \\
\hline $\begin{array}{l}\text { Severe PC and PTSD } \\
\text { symptoms (ref PC } \\
\text { symptoms) }\end{array}$ & 0.71 & $0.45-1.12$ & 0.141 & 0.52 & $0.32-0.84$ & 0.007 & 0.76 & $\begin{array}{l}-0.42- \\
1.37\end{array}$ & 0.358 & 1.07 & $0.63-1.84$ & 0.799 \\
\hline $\begin{array}{l}\text { PTSD symptoms (ref PC } \\
\text { symptoms) }\end{array}$ & 1.29 & $0.51-3.30$ & 0.595 & 0.62 & $0.27-1.46$ & 0.275 & 0.99 & $0.36-2.72$ & 0.985 & 0.33 & $0.08-1.42$ & 0.136 \\
\hline \multicolumn{13}{|l|}{ Adjusted $^{1}$} \\
\hline $\begin{array}{l}\text { No/mild symptoms (ref PC } \\
\text { symptoms) }\end{array}$ & 1.00 & $0.70-1.41$ & 0.986 & 0.54 & $0.36-0.81$ & 0.003 & 0.95 & $0.62-1.45$ & 0.818 & 0.39 & $0.26-0.60$ & $<0.001$ \\
\hline $\begin{array}{c}\text { Severe PC and PTSD } \\
\text { symptoms (ref PC } \\
\text { symptoms) }\end{array}$ & 0.95 & $0.55-1.63$ & 0.843 & 0.42 & $0.20-0.84$ & 0.015 & 1.25 & $0.62-2.52$ & 0.538 & 1.39 & $0.77-2.49$ & 0.272 \\
\hline $\begin{array}{l}\text { PTSD symptoms (ref PC } \\
\text { symptoms) }\end{array}$ & 2.04 & $0.71-5.80$ & 0.184 & 0.60 & $0.17-2.12$ & 0.428 & 1.97 & $0.61-6.41$ & 0.259 & 0.37 & $0.07-1.88$ & 0.231 \\
\hline
\end{tabular}

Abbreviations: PC = post-concussion, $\mathrm{PTSD}=$ post-traumatic stress disorder, $\mathrm{ICU}=$ intensive care unit, $\mathrm{OR}=$ odds ratio. ${ }^{1}$ Adjusted for age, sex, educational level, psychiatric history, and injury severity score.

Table A3. HRQoL for patients who had ongoing rehabilitation care or not at 6 months.

\begin{tabular}{ccccccccc}
\hline & \multicolumn{2}{c}{ No/Mild Symptoms } & \multicolumn{2}{c}{ Severe PC Symptoms, No } & \multicolumn{2}{c}{$\begin{array}{c}\text { PTSD, No Severe PC } \\
\text { PTSD }\end{array}$} & \multicolumn{2}{c}{$\begin{array}{c}\text { Severe PC and PTSD } \\
\text { Symptoms }\end{array}$} \\
\hline $\begin{array}{c}\text { Rehabilitation } \\
\text { at 6 Months }\end{array}$ & $\begin{array}{c}\text { No Rehab } \\
\text { Care }\end{array}$ & Ongoing & $\begin{array}{c}\text { No Rehab } \\
\text { Care }\end{array}$ & Ongoing & $\begin{array}{c}\text { No Rehab } \\
\text { Care }\end{array}$ & Ongoing & $\begin{array}{c}\text { No Rehab } \\
\text { Care }\end{array}$ & $\begin{array}{c}\text { Ongoing } \\
\text { SF-12 PCS }\end{array}$ \\
$49.3(9.1)$ & $43.3(10.6)$ & $40.6(11.4)$ & $37.8(9.8)$ & $47.9(10.5)$ & $39.2(11.4)$ & $39.9(10.5)$ & $36.0(11.4)$ \\
\hline SF-12 MCS & $52.2(8.7)$ & $50.1(8.5)$ & $41.6(10.4)$ & $40.4(8.9)$ & $36.5(8.6)$ & $42.8(14.7)$ & $31.3(9.6)$ & $32.7(9.9)$ \\
\hline QoLIBRI-OS & $77.4(16.6)$ & $71.8(15.1)$ & $55.4(18.9)$ & $50.9(17.0)$ & $52.7(21.4)$ & $50.0(29.7)$ & $41.3(20.5)$ & $45.0(24.9)$ \\
\hline
\end{tabular}

Abbreviations: $\mathrm{PC}=$ post-concussion, $\mathrm{PTSD}=$ post-traumatic stress disorder, $\mathrm{HRQoL}=$ health-related quality of life, $\mathrm{SF}-12 \mathrm{PCS}=12$-item Short Form Health Survey-Version 2 physical component score, SF-12 PCS = 12-item Short Form Health Survey-Version 2 mental component score, QoLIBRI-OS = Quality of Life after Brain Injury Overall Scale.

Table A4. Injury Severity Score for patients with and without ongoing rehabilitation at 6 months.

\begin{tabular}{|c|c|c|c|c|c|c|c|c|}
\hline & \multicolumn{2}{|c|}{ No/Mild Symptoms } & \multicolumn{2}{|c|}{$\begin{array}{c}\text { Severe PC Symptoms, } \\
\text { No PTSD }\end{array}$} & \multicolumn{2}{|c|}{$\begin{array}{c}\text { PTSD, No Severe PC } \\
\text { Symptoms }\end{array}$} & \multicolumn{2}{|c|}{$\begin{array}{c}\text { Severe PC and PTSD } \\
\text { Symptoms }\end{array}$} \\
\hline $\mathrm{N}$ & \multicolumn{2}{|c|}{$540(47.8 \%)$} & \multicolumn{2}{|c|}{$138(48.6 \%)$} & \multicolumn{2}{|c|}{$16(55.2 \%)$} & \multicolumn{2}{|c|}{$66(53.2 \%)$} \\
\hline $\begin{array}{l}\text { Ongoing rehabilitation at } \\
\qquad 6 \text { months }\end{array}$ & No & Yes & No & Yes & No & Yes & No & Yes \\
\hline ISS, mean (SD) & $\begin{array}{l}12.2 \\
(9.6)\end{array}$ & $\begin{array}{c}20.3 \\
(12.0)\end{array}$ & $\begin{array}{c}15.0 \\
(11.5)\end{array}$ & $\begin{array}{c}27.1 \\
(17.1)\end{array}$ & $\begin{array}{c}13.2 \\
(10.8)\end{array}$ & $\begin{array}{c}35.0 \\
(33.9)\end{array}$ & $\begin{array}{c}13.5 \\
(12.4)\end{array}$ & $\begin{array}{c}18.2 \\
(13.5)\end{array}$ \\
\hline
\end{tabular}

Abbreviations: PC = post-concussion, PTSD = post-traumatic stress disorder, ISS = Injury Severity Score.

Table A5. Logistic regression analysis on 6-month return to work.

\begin{tabular}{|c|c|c|c|c|c|c|}
\hline & \multicolumn{3}{|c|}{ Unadjusted } & \multicolumn{3}{|c|}{ Adjusted $^{1}$} \\
\hline & OR & CI $(95 \%)$ & $p$-Value & OR & CI $(95 \%)$ & $p$-Value \\
\hline No/mild symptoms (ref PC symptoms) & 0.17 & $0.11-0.26$ & $<0.001$ & 0.21 & $0.14-0.34$ & $<0.001$ \\
\hline Severe PC and PTSD symptoms (ref PC symptoms) & 0.51 & $0.18-1.50$ & 0.223 & 0.49 & $0.15-1.63$ & 0.246 \\
\hline PTSD symptoms (ref PC symptoms) & 0.60 & $0.32-1.10$ & 0.099 & 0.82 & $0.42-1.63$ & 0.575 \\
\hline
\end{tabular}

Abbreviations: $\mathrm{PC}=$ post-concussion, $\mathrm{PTSD}=$ post-traumatic stress disorder, $\mathrm{OR}=$ odds ratio; odds of not returning to work/returning to work at reduced level in relation to odds of returning to work at full level. ${ }^{1}$ Adjusted for age, sex, educational level, psychiatric history, and injury severity score. 
Table A6. HRQoL for patients who returned to work at full level or did not at 6 months.

\begin{tabular}{|c|c|c|c|c|c|c|c|c|}
\hline \multirow[b]{3}{*}{ Return to work } & \multicolumn{2}{|c|}{ No/Mild Symptoms } & \multicolumn{2}{|c|}{$\begin{array}{c}\text { Severe PC Symptoms, } \\
\text { no PTSD }\end{array}$} & \multicolumn{2}{|c|}{$\begin{array}{c}\text { PTSD, No Severe PC } \\
\text { Symptoms }\end{array}$} & \multicolumn{2}{|c|}{$\begin{array}{c}\text { Severe PC and PTSD } \\
\text { Symptoms }\end{array}$} \\
\hline & \multicolumn{2}{|c|}{$540(47.8 \%)$} & \multicolumn{2}{|c|}{$138(48.6 \%)$} & \multicolumn{2}{|c|}{$16(55.2 \%)$} & \multicolumn{2}{|c|}{$>66(53.2 \%)$} \\
\hline & Full RTW & No RTW & Full RTW & No RTW & Full RTW & No RTW & Full RTW & No RTW \\
\hline SF-12 PCS & $52.8(6.3)$ & $43.1(11.0)$ & $48.2(7.9)$ & $38.6(9.2)$ & $54.6(4.3)$ & $38.9(8.4)$ & $43.3(10.8)$ & $36.3(11.4)$ \\
\hline SF-12 MCS & $52.7(7.7)$ & $51.0(10.0)$ & $41.0(10.4)$ & $41.7(9.5)$ & $37.2(36.6)$ & $34.9(7.2)$ & $31.9(9.7)$ & $32.3(9.1)$ \\
\hline QoLIBRI-OS & $82.1(14.3)$ & $70.5(16.4)$ & $63.4(17.5)$ & $50.7(18.2)$ & $58.3(20.3)$ & $46.5(20.8)$ & $46.9(16.4)$ & $45.5(25.0)$ \\
\hline
\end{tabular}

Abbreviations: PC = post-concussion, $\mathrm{PTSD}=$ post-traumatic stress disorder, $\mathrm{HRQoL}=$ health-related quality of life, $\mathrm{SF}-12 \mathrm{PCS}=12$-item Short Form Health Survey-Version 2 physical component score, SF-12 PCS = 12-item Short Form Health Survey-Version 2 mental component score, QoLIBRI-OS = Quality of Life after Brain Injury Overall Scale, RTW = return to work.

Table A7. Injury Severity Score for patients who returned to work at full level or did not at 6 months.

\begin{tabular}{|c|c|c|c|c|c|c|c|c|}
\hline & \multicolumn{2}{|c|}{$\begin{array}{c}\text { No Severe PC/PTSD } \\
\text { Symptoms }\end{array}$} & \multicolumn{2}{|c|}{$\begin{array}{c}\text { Severe PC Symptoms, } \\
\text { No PTSD }\end{array}$} & \multicolumn{2}{|c|}{$\begin{array}{c}\text { PTSD, No Severe PC } \\
\text { Symptoms }\end{array}$} & \multicolumn{2}{|c|}{$\begin{array}{c}\text { Severe PC and PTSD } \\
\text { Symptoms }\end{array}$} \\
\hline $\mathrm{N}$ & \multicolumn{2}{|c|}{$540(47.8 \%)$} & \multicolumn{2}{|c|}{$138(48.6 \%)$} & \multicolumn{2}{|c|}{$16(55.2 \%)$} & \multicolumn{2}{|c|}{$66(53.2 \%)$} \\
\hline Return to work & Full RTW & No RTW & Full RTW & No RTW & Full RTW & No RTW & Full RTW & No RTW \\
\hline ISS, mean (SD) & $\begin{array}{l}11.3 \\
(8.8)\end{array}$ & $\begin{array}{c}22.1 \\
(15.0)\end{array}$ & $\begin{array}{l}13.8 \\
(9.4)\end{array}$ & $\begin{array}{c}23.7 \\
(17.0)\end{array}$ & $\begin{array}{c}19.5 \\
(19.0)\end{array}$ & $\begin{array}{l}14.5 \\
(8.7)\end{array}$ & $\begin{array}{c}11.3 \\
(10.0)\end{array}$ & $\begin{array}{l}15.7 \\
(13.6)\end{array}$ \\
\hline
\end{tabular}

Abbreviations: PC = post-concussion, PTSD = post-traumatic stress disorder, ISS = Injury Severity Score, RTW = return to work.

\section{References}

1. Maas, A.I.R.; Menon, D.K.; Adelson, P.D.; Andelic, N.; Bell, M.J.; Belli, A.; Bragge, P.; Brazinova, A.; Büki, A.; Chesnut, R.M.; et al. Traumatic brain injury: Integrated approaches to improve prevention, clinical care, and research. Lancet Neurol. 2017, 16, 987-1048. [CrossRef]

2. Menon, D.K.; Schwab, K.; Wright, D.; Maas, A.I. Position Statement: Definition of Traumatic Brain Injury. Arch. Phys. Med. Rehabil. 2010, 91, 1637-1640. [CrossRef] [PubMed]

3. Van der Naalt, J.; Timmerman, M.E.; de Koning, M.E.; van der Horn, H.J.; Scheenen, M.E.; Jacobs, B.; Hageman, G.; Yilmaz, T.; Roks, G.; Spikman, J.M. Early predictors of outcome after mild traumatic brain injury (UPFRONT): An observational cohort study. Lancet Neurol. 2017, 16, 532-540. [CrossRef]

4. Konrad, C.; Geburek, A.J.; Rist, F.; Blumenroth, H.; Fischer, B.; Husstedt, I.; Arolt, V.; Schiffbauer, H.; Lohmann, H. Long-term cognitive and emotional consequences of mild traumatic brain injury. Psychol. Med. 2010, 41, 1197-1211. [CrossRef]

5. Smith-Seemiller, L.; Fow, N.R.; Kant, R.; Franzen, M.D. Presence of post-concussion syndrome symptoms in patients with chronic pain vs. mild traumatic brain injury. Brain Inj. 2003, 17, 199-206. [CrossRef] [PubMed]

6. Bryant, R.A.; Harvey, A.G. Postconcussive Symptoms and Posttraumatic Stress Disorder after Mild Traumatic Brain Injury. J. Nerv. Ment. Dis. 1999, 187, 302-305. [CrossRef]

7. Karr, J.E.; Iverson, G.L.; Berghem, K.; Kotilainen, A.-K.; Terry, D.P.; Luoto, T.M. Complicated mild traumatic brain injury in older adults: Post-concussion symptoms and functional outcome at one week post injury. Brain Inj. 2020, 34, 26-33. [CrossRef] [PubMed]

8. Voormolen, D.C.; Haagsma, J.A.; Polinder, S.; Maas, A.I.; Steyerberg, E.W.; Vuleković, P.; Sewalt, C.A.; Gravesteijn, B.Y.; Covic, A.; Andelic, N.; et al. Post-Concussion Symptoms in Complicated vs. Uncomplicated Mild Traumatic Brain Injury Patients at Three and Six Months Post-Injury: Results from the CENTER-TBI Study. J. Clin. Med. 2019, 8, 1921. [CrossRef]

9. McMillan, T.M.; Williams, W.H.; Bryant, R. Post-traumatic stress disorder and traumatic brain injury: A review of causal mechanisms, assessment, and treatment. Neuropsychol. Rehabil. 2003, 13, 149-164. [CrossRef]

10. Van Praag, D.L.; Cnossen, M.C.; Polinder, S.; Wilson, L.; Maas, A.I. Post-Traumatic Stress Disorder after Civilian Traumatic Brain Injury: A Systematic Review and Meta-Analysis of Prevalence Rates. J. Neurotrauma 2019, 36, 3220-3232. [CrossRef]

11. Asmundson, G.J.; Frombach, I.; McQuaid, J.; Pedrelli, P.; Lenox, R.; Stein, M.B. Dimensionality of posttraumatic stress symptoms: A confirmatory factor analysis of DSM-IV symptom clusters and other symptom models. Behav. Res. Ther. 2000, 38, 203-214. [CrossRef]

12. Friedman, M.J.; Resick, P.A.; Bryant, R.A.; Brewin, C.R. Considering PTSD for DSM. Depress. Anxiety 2011, 28, 750-769. [CrossRef]

13. Lagarde, E.; Salmi, L.-R.; Holm, L.W.; Contrand, B.; Masson, F.; Ribéreau-Gayon, R.; Laborey, M.; Cassidy, J.D. Association of Symptoms Following Mild Traumatic Brain Injury with Posttraumatic Stress Disorder vs. Postconcussion Syndrome. JAMA Psychiatry 2014, 71, 1032-1040. [CrossRef] [PubMed]

14. Polinder, S.; Cnossen, M.C.; Real, R.G.L.; Covic, A.; Gorbunova, A.; Voormolen, D.C.; Master, C.; Haagsma, J.A.; Diaz-Arrastia, R.; Von Steinbuechel, N. A Multidimensional Approach to Post-concussion Symptoms in Mild Traumatic Brain Injury. Front. Neurol. 2018, 9, 1113. [CrossRef] 
15. Bryant, R.A. Posttraumatic stress disorder and traumatic brain injury: Can they co-exist? Clin. Psych. Rev. 2001, 21, 931-948. [CrossRef]

16. Haagsma, J.A.; Scholten, A.C.; Andriessen, T.M.; Vos, P.E.; Van Beeck, E.F.; Polinder, S. Impact of Depression and Post-Traumatic Stress Disorder on Functional Outcome and Health-Related Quality of Life of Patients with Mild Traumatic Brain Injury. J. Neurotrauma 2015, 32, 853-862. [CrossRef] [PubMed]

17. Voormolen, D.C.; Polinder, S.; von Steinbuechel, N.; Vos, P.E.; Cnossen, M.C.; Haagsma, J.A. The association between postconcussion symptoms and health-related quality of life in patients with mild traumatic brain injury. Injury 2019, 50, 1068-1074. [CrossRef] [PubMed]

18. Stulemeijer, M.; Van Der Werf, S.; Borm, G.F.; Vos, P.E. Early prediction of favourable recovery 6 months after mild traumatic brain injury. J. Neurol. Neurosurg. Psychiatry 2008, 79, 936-942. [CrossRef] [PubMed]

19. Emanuelson, I.; Holmkvist, E.A.; Björklund, R.; Stålhammar, D. Quality of life and post-concussion symptoms in adults after mild traumatic brain injury: A population-based study in western Sweden. Acta Neurol. Scand. 2003, 108, 332-338. [CrossRef] [PubMed]

20. Scholten, A.; Haagsma, J.; Andriessen, T.; Vos, P.; Steyerberg, E.; van Beeck, E.; Polinder, S. Health-related quality of life after mild, moderate and severe traumatic brain injury: Patterns and predictors of suboptimal functioning during the first year after injury. Injury 2015, 46, 616-624. [CrossRef] [PubMed]

21. Stålnacke, B.-M. Community integration, social support and life satisfaction in relation to symptoms 3 years after mild traumatic brain injury. Brain Inj. 2007, 21, 933-942. [CrossRef] [PubMed]

22. Maas, A.I.; Menon, D.K.; Steyerberg, E.W.; Citerio, G.; Lecky, F.; Manley, G.T.; Hill, S.; Legrand, V.; Sorgner, A. Collaborative European NeuroTrauma effectiveness research in traumatic brain injury (CENTER-TBI) a prospective longitudinal observational study. Neurosurgery 2015, 76, 67-80. [CrossRef]

23. Steyerberg, E.W.; Wiegers, E.; Sewalt, C.; Buki, A.; Citerio, G.; De Keyser, V.; Ercole, A.; Kunzmann, K.; Lanyon, L.; Lecky, F.; et al. Case-mix, care pathways, and outcomes in patients with traumatic brain injury in CENTER-TBI: A European prospective, multicentre, longitudinal, cohort study. Lancet Neurol. 2019, 18, 923-934. [CrossRef]

24. King, N.S.; Crawford, S.; Wenden, F.J.; Moss, N.E.G.; Wade, D.T. The Rivermead Post Concussion Symptoms Questionnaire: A measure of symptoms commonly experienced after head injury and its reliability. J. Neurol. 1995, 242, 587-592. [CrossRef] [PubMed]

25. Blevins, C.A.; Weathers, F.W.; Davis, M.T.; Witte, T.K.; Domino, J.L. The PTSD Checklist for DSM-5 (PCL-5). Available online: www.ptsd.va.gov (accessed on 1 March 2021).

26. Gennarelli, T.A.; Wodzin, E. Abbreviated Injury Scale 2005: Update 2008; Russ Reeder: Redwood City, CA, USA, 2008.

27. Teasdale, G.; Jennett, B. Assessment of coma and impaired consciousness: A practical scale. Lancet 1974, 304, 81-84. [CrossRef]

28. Thompson, C.; Davies, P.; Herrmann, L.; Summers, M.; Potter, S. Approaches to establishing validated cut-off scores on the Rivermead post-concussion symptoms questionnaire (RPQ). In Brain Injury; Taylor \& Francis, Inc.: Philadelphia, PA, USA, 2016.

29. American Psychiatric Association. Diagnostic and Statistical Manual of Mental Disorders (DSM-5®); American Psychiatric Association: Washington, DC, USA, 2013.

30. Bovin, M.J.; Marx, B.P.; Weathers, F.W.; Gallagher, M.W.; Rodriguez, P.; Schnurr, P.P.; Keane, T. Psychometric properties of the PTSD Checklist for Diagnostic and Statistical Manual of Mental Disorders-Fifth Edition (PCL-5) in veterans. Psychol. Assess. 2016, 28, 1379-1391. [CrossRef]

31. Ware, J.E., Jr.; Kosinski, M.; Keller, S.D. A 12-Item Short-Form Health Survey: Construction of scales and preliminary tests of reliability and validity. Med. Care 1996, 34, 220-233. [CrossRef] [PubMed]

32. Wilson, L.; Marsden-Loftus, I.; Koskinen, S.; Bakx, W.; Bullinger, M.; Formisano, R.; Maas, A.; Neugebauer, E.; Powell, J.; Sarajuuri, J.; et al. Interpreting quality of life after brain injury scores: Cross-walk with the short form. J. Neurotrauma 2017, 34, 59-65. [CrossRef] [PubMed]

33. Von Steinbuechel, N.; Wilson, L.; Gibbons, H.; Muehlan, H.; Schmidt, H.; Schmidt, S.; Sasse, N.; Koskinen, S.; Sarajuuri, J.; Hoefer, S.; et al. QOLIBRI Overall Scale: A brief index of health-related quality of life after traumatic brain injury. J. Neurol. Neurosurg. Psychiatry 2012, 83, 1041-1047. [CrossRef]

34. Cohen, J. Set Correlation and Contingency Tables. Appl. Psychol. Meas. 1988, 12, 425-434. [CrossRef]

35. Polinder, S.; Haagsma, J.A.; Van Klaveren, D.; Steyerberg, E.W.; Van Beeck, E.F. Health-related quality of life after TBI: A systematic review of study design, instruments, measurement properties, and outcome. Popul. Heal. Metr. 2015, 13, 1-12. [CrossRef]

36. Mols, F.; Pelle, A.J.; Kupper, N. Normative data of the SF-12 health survey with validation using postmyocardial infarction patients in the Dutch population. Qual. Life Res. 2009, 18, 403-414. [CrossRef] [PubMed]

37. Molina, R.T.; Munoz, F. References Values and Validation of the Spanish Version of the SF-12. Barranquilla, Colombia, 2012. J. Psychol. Psychother. 2012, 5, 2161-2487. [CrossRef]

38. Arango-Lasprilla, J.C.; Zeldovich, M.; Olabarrieta-Landa, L.; Forslund, M.V.; Núñez-Fernández, S.; Von Steinbuechel, N.; Howe, E.I.; Røe, C.; Andelic, N.; CENTER-TBI Participants and Investigators. Early Predictors of Employment Status One Year Post Injury in Individuals with Traumatic Brain Injury in Europe. J. Clin. Med. 2020, 9, 2007. [CrossRef] [PubMed]

39. Mackenzie, A.; Fountain, R.; Alfred, D.; Combs, D. Quality of Life and Adaptation for Traumatic Brain Injury Survivors: Assessment of the Disability Centrality Model. J. Rehabil. 2015, 81, 3. 
40. Mahar, C.; Fraser, K. Barriers to Successful Community Reintegration Following Acquired Brain Injury (ABI). Int. J. Disabil. Manag. 2011, 6, 49-67. [CrossRef]

41. Silverberg, N.D.; Iverson, G.L. Etiology of the post-concussion syndrome: Physiogenesis and psychogenesis revisited. NeuroRehabilitation 2011, 29, 317-329. [CrossRef] [PubMed]

42. Snell, D.L.; Macleod, A.D.S.; Anderson, T. Post-Concussion Syndrome after a Mild Traumatic Brain Injury: A Minefield for Clinical Practice. J. Behav. Brain Sci. 2016, 6, 227-232. [CrossRef]

43. Carroll, L.J.; Cassidy, J.D.; Cancelliere, C.; Côté, P.; Hincapié, C.A.; Kristman, V.L.; Holm, L.W.; Borg, J.; Boussard, C.N.-D.; Hartvigsen, J. Systematic Review of the Prognosis After Mild Traumatic Brain Injury in Adults: Cognitive, Psychiatric, and Mortality Outcomes: Results of the International Collaboration on Mild Traumatic Brain Injury Prognosis. Arch. Phys. Med. Rehabil. 2014, 95, S152-S173. [CrossRef]

44. Silver, J.M. Effort, exaggeration and malingering after concussion: Figure. J. Neurol. Neurosurg. Psychiatry 2012, 83, 836-841. [CrossRef] [PubMed]

45. Van Praag, D.L.G.; Fardzadeh, H.E.; Covic, A.; Maas, A.I.R.; Von Steinbüchel, N. Preliminary validation of the Dutch version of the Posttraumatic stress disorder checklist for DSM-5 (PCL-5) after traumatic brain injury in a civilian population. PLoS ONE 2020, 15, e0231857. [CrossRef]

46. Ashbaugh, A.R.; Houle-Johnson, S.; Herbert, C.; El-Hage, W.; Brunet, A. Psychometric Validation of the English and French Versions of the Posttraumatic Stress Disorder Checklist for DSM-5 (PCL-5). PLoS ONE 2016, 11, e0161645. [CrossRef] [PubMed]

47. Kraemer, H.C.; Morgan, G.A.; Leech, N.L.; Gliner, J.A.; Vaske, J.J.; Harmon, R.J. Measures of Clinical Significance. J. Am. Acad. Child Adolesc. Psychiatry 2003, 42, 1524-1529. [CrossRef] [PubMed]

48. Chen, H.; Cohen, P.; Chen, S. How Big Is a Big Odds Ratio? Interpreting the Magnitudes of Odds Ratios in Epidemiological Studies. Commun. Stat. Simul. Comput. 2010, 39, 860-864. [CrossRef]

49. Bell, K.R.; Hoffman, J.M.; Temkin, N.R.; Powell, J.M.; Fraser, R.T.; Esselman, P.C.; Barber, J.K.; Dikmen, S. The effect of telephone counselling on reducing post-traumatic symptoms after mild traumatic brain injury: A randomised trial. J. Neurol. Neurosurg. Psychiatry 2008, 79, 1275-1281. [CrossRef] [PubMed]

50. Al Sayegh, A.; Sandford, D.; Carson, A.J. Psychological approaches to treatment of postconcussion syndrome: A systematic review. J. Neurol. Neurosurg. Psychiatry 2010, 81, 1128-1134. [CrossRef] [PubMed] 